\title{
Material data matter - Standard data format for engineering materials
}

\author{
Dimitri Gagliardi \\ Manchester Institute of Innovation Research, AMBS Harold Hankins Building, Booth Street West, Manchester M13 9PL, UK
}

\section{A R T I C L E I N F O}

\section{Article history:}

Received 12 April 2015

Received in revised form 15 September 2015

Accepted 16 September 2015

Available online 14 October 2015

\section{Keywords:}

Innovation in materials data models

Standardisation

Materials data

Engineering materials

\begin{abstract}
A B S T R A C T
Standardisation is often linked to the very existence of an industry and its evolutionary dynamics especially in sectors where activities are particularly reliant on network economies. This paper investigates the interests of the stakeholders of the materials industry in the effort of setting the basis for standard-compliant formats for engineering materials test data used in materials test certificates (TCs). Test certificates provide a guarantee of origin, characteristics and materials specifications. A transition to standardised electronic-test certificates (ETCs) is thought to offer advantages over the static alternatives currently in use. This work highlights that the stakeholders involved in the process have a general need for a standard compliant data model yet their particular interests might not be completely aligned. The choice of an open, non-proprietary, data format and compatibility of the standard with legacy technological solutions prove to be critical for the implementation of standardised E-TCs.
\end{abstract}

() 2015 Elsevier Inc. All rights reserved.

\section{Introduction}

Test certificates are documents containing the results of a specific test (or battery of tests) performed on a given batch of material, carried out by an authorised testing house. The documents certify upon the characteristics of the materials submitted to testing procedures and follow the material along the production chain from the manufacturer to the final users. ${ }^{1}$ The intrinsic value of a TC is negligible as it can be reproduced and distributed at a very low marginal cost. However its economic value transcends the mere piece of paper onto which test results are reported and depends on the value it adds to the product it refers to. To understand the extent to which TCs are pervasive in the modern knowledge-based society one might think that nearly every component of a manufactured good is made of some sort of material whose characteristics have been assessed, tested and certified.

Regarding the widespread diffusion of TCs in our everyday life it is perhaps worth mentioning that a large number of tests is regularly carried out on the glass of a double-glazed window or of a patio door. These include, amongst others, 1) impact testing, 2) strength, 3) fragmentation, 4) stress, 5) humidity and boil, 6) heat, 7) gas leakage, 8) mist and fogging performance, 9) dew point measurement, 10) moisture absorption capacity and content, and 11) UV fogging. All these tests, carried out according to standards (BS EN 12150, 2004; BS EN 14449:2005, 2005; BS EN 1279-2, 2002; BS EN 1279-3, 1998; BS EN 1279-6, 2002),

\footnotetext{
E-mail address: dimitri.gagliardi@manchester.ac.uk.

1 In the United States and Canada, test certificates are known as mill test reports and related documentation is referred to as "certificates of conformance".
}

involve the production, transfer and management of a large quantity of data describing characteristics of the materials.

A second example relates to probably the toughest challenge of material engineering, that of the blade of a jet engine. The use of TCs in this case plays many critical roles in the entire blade's value chain. A blade in a jet engine used in civil aviation is part of a piece of technology that withstands extreme pressure (up to $700 \mathrm{psi}$ ), temperatures higher than the melting point of the component materials ( $2400 \mathrm{~K})$, huge acceleration $(50,000 \mathrm{~g})$ and the typical working life of a turbine blade is of about 10,000 h (Parsons et al., 2011). In this case, TCs and the data they represent are employed in research, development and design of new blades either through physical experiments - testing the capacity of prototypes to withstand working conditions - and in numerical simulations whereby new designs and new materials are played out in simulated experimental settings. Test certificates are also widely employed in order to test and report blades' performance against safety parameters and of course play an important part in the manufacturing process, in the transactions between blade manufacturers and other stakeholders in the aviation industry from jet engine system developers to carriers and aviation authorities which are seldom located within national borders let alone within the same premises.

These two examples show the formidable background behind the data generation process involved in assessing and certifying materials' characteristics yet they relate but to a part or a component of a larger artefact or technological system. This process is repeated countless times for each component of every product. When the product is part of a complex artefact such as a computer, an automobile or a telecommunication network which is made by many parts of different materials procured from different suppliers located all over the world, the materials 
certification process deals with an exceptionally high number of material test data.

TCs embody the network effect in an industry since the data generated through testing of each component constitute vital inputs into the various phases of production of any final industrial artefact within which said component is employed and has a compound effect during the whole life cycle of the products from material science and engineering research to R\&D and applications - discovery of new materials or better understanding of existing materials - to design and final product, subsequent audit trail and, finally, disposal.

Test certificates, providing a guarantee of the materials' specifications, are commonly made available in electronic format. These are static, often simply digitised images embedded in a PDF document, and offer little added-value compared to their conventional paper counterpart. A transition to E-TC generated from a content management system is thought to offer advantages over the paper-based alternatives, including that the original data can be traced and the output format can be tailored to the customer requirements. For this to happen it is necessary that the digitised information included in the E-TC is somehow standardised so that data handling can progress automatically.

Whilst TCs embody the network effect within a technological domain, standardised data formats and the subsequent implementation of E-TCs embody the economies of network deriving from the diffusion of an infrastructure for data management upon which different stakeholders may draw to base their TC-related processes and activities. ${ }^{2}$

The stakeholders in the certification process constitute the active counterparts in defining demand and supply. The demand side or the users of the TC, at a first approximation includes the final customers utilising the material in their research laboratories or production processes, but it extends also to audit organisations and quality control institutions. On the supply side, the interests of the manufacturers are sided by those of the test houses, ${ }^{3}$ the manufacturing and providers of testing machinery, and the software houses supplying reporting software.

These groups of stakeholders play a different but equally important role in setting the standards for quality and compatibility. Their interests lie in the business opportunities linked to the technological network in which they have stakes. In this specific case, where several proprietary data formats are currently used by the stakeholders of the materials sectors and without an emerging standard, the introduction of standardised data formats for E-TCs has the potential to disturb the balance of interests. The preliminary phases towards the design and implementation of a standard for machine readable, standard-compliant data model that is compatible with the existing systems of materials certification and the response of the stakeholders involved in the process are the principal concerns of this analysis. In other words, stakeholders' involvement in the preliminary phases of the process of data formats standardisation necessary for the transition to E-TCs is the object of this study. In particular, the analysis concerns the study of stakeholders' practices and interests in TCs and the matching between technology's characteristics and stakeholders' needs for a successful implementation of standardised data formats for test reporting.

The paper is organised as follows. Section 2 is concerned with the review of the literature on the technical aspects of standard compliant data format for engineering material test data. In the first part, the definitions of standards, the ways they come into general use and their impact on the development of technology are introduced and discussed. Then I will discuss the effects of standardisation of data

\footnotetext{
${ }^{2}$ By economy of network is here intended the type of economic environment that emerges from the introduction of standardised digital information whereby connections (and value) are derived from the services provided by the ICT infrastructure for data management and that such value increases for all stakeholders with the growing of the userbase of such infrastructure.

${ }^{3}$ Test houses can either be independent organisations or affiliated to the materials manufacturer.
}

formats and the interactions amongst the categories of actors along the value chain of the materials TCs by bringing evidence from the literature on this topic. The section concludes with a description of the methodology followed in conducting this study. Section 3 is dedicated to the description of the engineering material sector, its stakeholders and the roles of material TCs in their value chain. The stakeholders' interests are presented and analysed in Section 4. Here interests and strategies of the stakeholders involved in the engineering material test process are presented and discussed. Particular focus is given to the shaping of the value chain following the introduction of standard data format. The paper concludes with a discussion of the issues and further remarks.

\section{Insights from the literature and research objectives}

A standard can be defined as a set of technical specifications to which producers should agree either tacitly or through formal agreements. According to its specific functions, a standard can be a reference of quality or embed technical features. Quality standards set some conformity parameters for the characteristics of the material sold, used into a production process or exchanged; they are employed to provide indications that a product or a service adheres to determined characteristics (Akerlof, 1970; Leland, 1979; Ronnen, 1991; Dranove \& Jin, 2010). Alternatively, there are compatibility standards providing technical references according to which an intermediate product or a component can fit and operate within a larger technological system or operate as a subsystem of a more complex technology (David, 1987; Allen \& Sriram, 2000; Tassey, 2000; Langlois, 2001; Chen \& Liu, 2005; Hyvättinen, 2006).

The process through which a standard comes into general use and is adopted by an industry is of particular importance. In terms of the procedures through which a standard can be drafted the literature has identified 4 main routes. A standard can emerge 1) spontaneously from the interaction of stakeholders on the market through the competitive process; in this case the emergence of a standard is based on practices, uses and unsponsored conventions. Standards can also emerge 2) through market interaction when sponsored by one or more stakeholders with proprietary interests in the standard and, once established, induce other market players to adhere. These are known in the literature as de facto standards. A standard agreement can be reached 3 ) under the aegis of a standard setting organisation and introduced on the market place or 4) mandated by a regulatory authority, these are de jure standards (David \& Greenstein, 1990; Utterback, 1994; Blind, 2004).

In industrial settings, standardisation is often linked to the very existence of the industry and its evolutionary dynamics. Many studies have highlighted how standardisation issues affect deeply those sectors of economic activities where business is particularly reliant on network economies. Network effect occurs in those industries where the utility of the product (or the technological component) is linked to the degree of success of its integration in a wider technological system and economies of network for the stakeholders increase with the size of the network within which they are embedded (Katz \& Shapiro, 1985, 1994; Shapiro \& Varian, 1999). The presence of a standard within an industry is a significant factor in the affirmation of a technological system therefore, many economic agents operating within networked technological systems have strong interests in the diffusion of those standards that would provide them with a competitive edge (Blind, 2004; Katz \& Shapiro, 1985, 1994; Shapiro \& Varian, 1999, 2003). The history for dominance on the marketplace, where the diffusion of technologies are strongly contingent on prevailing standards, has been and still is well researched. Examples of these studies range from early electrification and standardisation of the electric supply systems of the late 19th century (David \& Bunn, 1988) to the prevailing of the QWERTY design on keyboards (David, 1985) and the battle between SONY and JVC on the BETAMAX-Video Home System Standard (Cusumano et al., 1992). 
More recent studies look at the opening up of Sun Microsystems own standard upon which Java Technology is based to allow further diffusion (Garud et al., 2002), the HD-DVD versus Blue Ray in the market for DVDs (Gallagher, 2012), the standardisation problem in the cloud computing market (Ortiz, 2011) or the more general integration of technology and standardisation challenges posed by the emergence of the Internet of Things (Bandyopadhyay \& Sen, 2011; Tsai et al., 2014).

The main message of these analyses for technological dominance is that standard settings, whether they initiate from within the industry, from negotiations between the industry and institutions, or somehow imposed/negotiated by institutions (Chiesa et al., 2002; Suarez, 2004; Van Wegberg, 2004), have a significant impact on the development of technologies, technological platforms and their evolutionary trajectories. In other words, there emerges causation between modes of standard setting and the diffusion of a technological trajectory and, in some sectors, this dynamics co-evolves also with that of the regulatory regime. Standardisation is usually one of the elements for which a certain technological solution or a preferred technological hierarchy becomes widely adopted. Wider adoption, in turn, defines the characteristics of the technological trajectories followed by the industry.

In fact, one of the main characteristics of a standard and its implications in business activities and economics is that the definition itself embeds into the demand function for a particular technology, product or services. More precisely, by adopting certain standardised procedures - either quality or compatibility standards - the service or product are automatically embedded in a particular technological network. The feedback effects entail that the extent of such networks is dependent upon the degree of generalisation of its components respect to the market or the technology into which they are embedded (Jakobs, 2006). The general effect on the whole industry will be that of consolidating business practices, opening new business opportunities and, in general, upgrade to a technological platform through a process of technological convergence (Gauch \& Blind, 2015).

In other words, by means of this dynamics, standards are valuable process infrastructure in exploiting increasing returns within a given domain. When increasing returns tend to taper off and lock-in sets in, then standard dynamics tends to provide novel sources to increasing returns (Dosi, 1982; David \& Bunn, 1988; Allen \& Sriram, 2000; Langlois, 2001; Chen \& Liu, 2005; Jakobs, 2006; Gauch \& Blind, 2015).

Blind \& Gauch (2009) and Goluchowicz \& Blind (2011) have delineated the use of standards in the various phases on the innovation process. In particular, different types of standards are associated with particular phases of the innovation process from basic/blue sky research to product/technology diffusion. Each type of standard responds to a function in the innovation process from the reduction of information and transaction costs to interoperability and eventually quality certification (Fig. 1 below).

Within this typology, standardised data models, introduce a further transversal layer which spans across all phases of the system of relations identified by Blind and Gauch (2009) and Goluchowicz and Blind (2011). The reason is that when we consider the application of TCs in each of the phases described by Blind and colleagues (Blind \& Gauch, 2009; Goluchowicz \& Blind, 2011) current practices do not yet foresee an integrated/standardised way of capturing and transferring the string of data describing materials' characteristics which are presented in TCs. Data are generated at various stages of the value chain according to standard guidelines: measurement and testing standards, interface standards, compatibility, quality and variety reducing standards. The results at each stage are then transmitted to the next either within the same business units or to third parties. Whilst standardised procedures for the conduction of test are generally available, standardised data formats for the capture, transmission and archive of test data are not. Therefore, stakeholders along the various stages of the innovation process are most often handling a great amount of data in a nonautomated or semi-automated way. The introduction of standardised data format would increase the likelihood of unifying the process of test data transfer and use across the various stages described above. This would be possible only if semantic/terminology standards were to be used for data capture and management at the origin of the data generation process and consistently throughout the stages of the innovation process. The semantic/terminology used relies on testing standards already in place and widely used in testing procedures. Under these conditions, standardised data format would extend their use and reach beyond 'linking fundamental research with directed research' and through the various stages of the research process up to the diffusion of the innovation and throughout the lifetime of the materials: from the science lab to final disposal.

Several novel and emerging industrial applications such as virtual production, digitisation of the production processes and smart factories (Xu, 2012; Kádár et al., 2013; Westkämper \& Jendoubi, 2003; Davis et al., 2012) rely heavily on the wider diffusion of standardised data formats since their manufacturing activities are substantially based on the elaboration of large quantity of materials data which would be possible only in the case where these could be reliably collected and collated. Nonetheless, standardisation of data formats, within this conceptual framework, is unanimously considered a very important milestone in any field concerned from material science and engineering (Ward et al., 2014) to complex product development (Swindells, 2002;

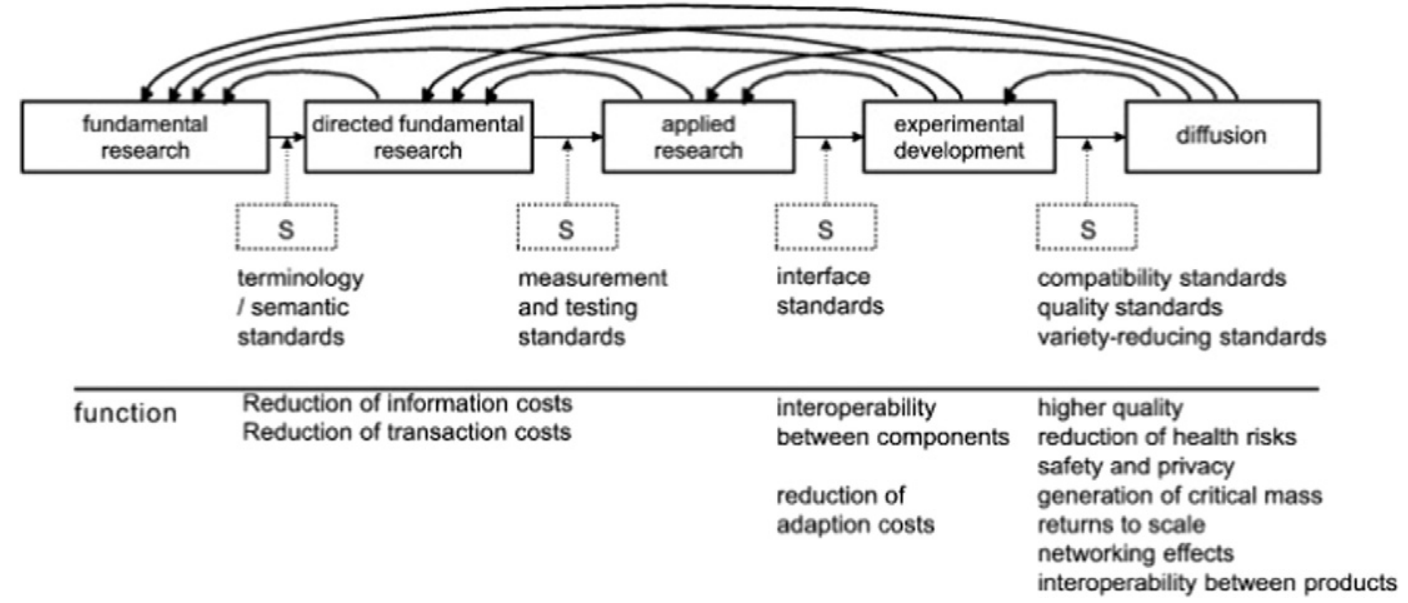

Fig. 1. Various roles of different types of standards in the innovation process. Sources: Blind and Gauch (2009) and Goluchowicz and Blind (2011). 
Cascini et al., 2005) and product and material disposal (Moreno et al., 2011). ${ }^{4}$ Standardised data formats are infrastructure ICT standards and, as such, their emergence is often the product of lengthy negotiations amongst the parties.

The involvement of stakeholders, defined as those who can affect or are affected by the objectives of the process, paraphrasing (Freeman, 1984; Freeman \& Miles, 2006), has attracted much research effort in management, engineering and policy domains amongst others (Fassin, 2009). In particular, setting de jure standards and initiating the process under the aegis of a standard agency would foster the objective of providing a common and open platform upon which the stakeholders can negotiate their sphere of influence and guarantee a fair implementation of the standardisation practices (CEN CWA 16762:2014, 2014).

Salado and Nilchiani (Salado \& Nilchiani, 2013) stress the importance of the correct identification of stakeholders as a mean to bring to the negotiation table all the interested parties in order to suitably define the problem at hand. The process of identification of the stakeholders involved in the standardisation process is therefore crucial in order to draw the basis for a shared understanding which reflects the interests of all parties. By bringing to the negotiation table mutually accepted stakeholders, the standard will have better chances of being widely adopted and make a positive impact on the specific domains of application (De Vries et al., 2003; Saltzman et al., 2008).

Thus far we have seen that standardisation is determinant in a networked environment, sometimes even critical for its existence. This process is important for the material science as well as for public and private research organisations. It has equally significant repercussions in material science and engineering and in the closed/proprietary data management departments of engineering and manufacturing businesses (Westbrook, 2003). In a context such as materials whereby standardisation is already pervasive in all aspects of testing from the objectives of a test, definitions, parameterisations and testing conditions, there does not exists, at present, a standardised data model able to capture the information produced and therefore translate the test results in machine readable format.

The present study looks at the preparatory phases to devise standards for the capture of material test data so that they could be made available and interpretable by machines in order to insure the functions of certification for the lifecycle of the materials independently from the static TCs currently in use.

\subsection{Methodology of the study.}

The study adopted a qualitative approach; it consisted in the active participation of the author in conducting the business analysis for the explorative study preparing for the introduction of standardised E-TCS (Reason \& Bradbury, 2001) and a case study approach in order to draw directly from the stakeholders information about the practices followed in their TC management and their interests in the transition to E-TC (Eisenhardt, 1989; Meredith, 1998; Yin, 2013). ${ }^{5}$

The study has been conducted during a period of 15 months in 2009 and 2010. In this period 4 workshops were held in Brussels, London and Delft where a series of face-to-face interviews with the participants were conducted. Other interviews were conducted also via email and over the telephone.

\footnotetext{
${ }^{4}$ The importance of the theme is also evidenced in several other areas where data model standardisation has been at the centre of lengthy debates and negotiations, for example in the field of proteomics, (Orchard et al., 2004, 2013) or when it constituted the turning point of innovative activities (Poore, 2011).

5 These activities were aiming at establishing "proof of concept" for the introduction of the standardised data formats for the engineering test data amongst the stakeholders including industrial partners, university and research centres and standardisation institutions (CEN CWA 16200:2010, 2010). Subsequently, the European Committee for Standardisation (CEN) advanced on the finding of the 'Guide' and requested that applied technical case studies were to be conducted (SERES).
}

The routine workshops were organised in a formal setting whereby the findings of desk-based research and information/knowledge collected during previous research phases were presented to the stakeholders and tested openly so that the issues could be either simply validated or discussed, extended, amended and challenged. During this phase new operative and/or conceptual issues emerged. These issues were then taken up and discussed with the stakeholders in order to understand their points of view, identify important factors, straighten out misunderstandings and identify the many nuances of the process as they emerged. The observations obtained through these discussions were then collated in the working documents and submitted to the stakeholders for a formal review process.

Moreover, a short interview pro forma was administered through a semi-structured questionnaire via email and telephone follow-ups were undertaken. Fourteen organisations participated to this phase, covering over $40 \%$ of the stakeholders involved in the process. These were selected in order to represent all stages/links in the TCs value chain. Respondents and their organisations were engaged in more than one link of the TCs value chain and comprised 3 manufacturing companies including 1 original equipment manufacturer, 1 subcontractor manufacturer and 1 alloy producer; 1 TC customer; 5 test laboratories; 1 test machinery manufacturer; 2 software houses; 8 stakeholders engaged in R\&D of which 2 university departments, 1 public research centre, 1 private research organisation and 1 company research laboratory; 2 publishers; 2 third party services providers and 2 life-cycle analysts. The themes of the interviews were focussed on understanding whether TCs had a prominent place in the business model of the organisation or they were complementary to other key organisational functions. Moreover, the interviews were aiming at understanding if the organisations had in place knowledge management systems and to what extent TCs were therein integrated. A summary of the interviews was then collated, analysed and presented at a workshop where the outcome was discussed and further developed with the contribution of the workshop participants.

Additional insights were collected at the final workshop during the presentation of the draft report " $\mathrm{A}$ Guide to the Development and Use of Standards Compliant Data Formats for Engineering Materials Test Data" (CEN CWA 16200:2010, 2010) submitted to all participating stakeholders for a final revision before its approval and publication by the European Committee for Standardisation (CEN).

The results of the technical case studies included in CEN CWA 16762:2014 (2014) have also been used to inform this research paper.

Various organisations, from the material science and engineering research sectors, material manufacturing, testing machinery manufacturing, software houses and materials service providers were involved in the project. The list of the organisations participating to the research is presented in annex.

\section{Test certificates value chain and stakeholders}

The typical life cycle of a certificate is linked to the manufacturing process of the material it relates to. Accompanying the material throughout its life-cycle, the certificate provides an assurance to the customer that properties and characteristics of the product meet the demanded specifications. For the results to be credible, the test certificate indicates compliance with standardised test.

The certification process and the services rendered by TCs extend to a wider set of stakeholders in the certification business including intermediaries besides the testing houses since the certification is not only limited to providing an assurance to a customer. They are important documents for materials science and engineering, research and development activities, auditing, tracing, and guaranteeing long-term availability of a given product up to the product/material disposal after its working life. Correspondingly, the group of stakeholders in the standardisation of data models, aside from the manufacturer and 
its customers, includes also intermediaries that have vested interests in steering the final users' and suppliers' preferences towards the technological platform they have adopted in order to sustain their business model, justify the investments undertaken in the implemented procedures, and eventually maintain or increase their market share. Deviations from, and impacts on, specific stages in the existing value chain have been here studied by probing into the stakeholders' experience with machine readable TCs and their views on the impact that a standardised version of data models can have on their internal value creation operations.

The participants to this study have vested interests in the standardisation process, some of these are of a practical nature such as cost reduction, increased efficiency in operations and preparedness; some are of a more strategic nature. Some stakeholders, in fact, see their participation to this and similar study as an opportunity for steering the process towards standardisation choices that would leverage their competitive strengths. Although this study regards the exploratory phase, before a standardisation process can be initiated, stakeholders were directly - and voluntarily - involved in this study moved by both practical reasons and strategic behaviours. These will be singled out and discussed below. Their general characteristics, comprising a brief description of their stated interests in TCs and the value creation along the process from research and development to production, sale of the materials and post-sale auditing and disposal are concisely described in the following classification. In the table we have also included intermediaries, complementary industries and related users of the certificates that are relevant to the work conducted since they have stakes in the TCs business.

\section{Stakeholders' interests}

For an effective transition towards E-TCs, the structure and the elements of a test result need to be translated into a format which is "known and interpretable" by a machine. For any data format to be identifiable and interpretable by a machine it is necessary that identification tags can be univocally associated to each element of a standardised test. This way, each data point generated can be unambiguously identified and described - by its metadata - in a machine readable language. Then, it can be processed through data management procedures. Eventually, the certificates required can be produced electronically or in print (CEN CWA 16200:2010, 2010); Austin et al., 2013.

Technically, the introduction of machine readable data models for standardised E-TCs requires three main steps.

1) The standardised tests already in use in the materials sector need to be translated into natural language text structures (ontologies). These are able to draw on the instructions contained in the test standard documents and express them in logic sequences.

2) A unified modelling language (UML) needs to be devised in order to describe the ontologies linking the logic sequences from the test standards to the data capture and

3) Extensible markup language (XML) schemas need to be put in place in order to create the semantics of the elements defined in the ontologies and the UML.

In simpler terms, static certificates, even in their electronic format, are currently designed upon meta-languages used only to display rather than classify and describe - data in the format in which test machines' software are programmed. The layouts of these data in a static format are determined by the needs of the clients who define the content of the certificate or the test report so that it can be displayed, printed and archived. The introduction of a standard data model for E-TCs requires that the elements constituting the results of a test are univocally identified and described so that the resulting data can be interconnected and systemically integrated following standard test documentation instructions Table 1.

\subsection{What does it take to implement the technical aspects into a} standardised data model for the stakeholders?

Material manufacturers identify many shortcomings in the use of static certification. These are mainly linked to the phases of handling, archiving and retrieval. Updating data and information on materials has also been identified as an important hurdle for the management of the certificates. The main problems originate from the structural rigidity associated with the static certificates. This is to say that the operations, given the nature of the documents, are to be conducted manually. These are time and resource consuming and subjected to recurring errors. Mistakes are mainly occurring during the operations of translating paper-based certificates in electronic format; a process which increases the number of operations (i.e. data translation and data entry) and increases also the chance of deterioration of the data quality at each stage. Although in most cases TCs are already issued in electronic format, the transaction costs deriving from the non-conformity of the content to a common standard are felt as the principal bottleneck to their efficient handling and management. In many instances the respondents refer that their organisations are currently engaged with the implementation of new and more efficient data handling and management systems and the presence of standardised E-TC data model would greatly improve cost-effectiveness of the transition to networked knowledge management systems and database applications.

The reasons for this keenness relate directly to the issues of efficien$\mathrm{cy}$, reduction of transaction costs in the internal management of the test results and the relations with their customers. Also, a host of specific factors was highlighted:

- Data format and their integration within the management system (either in place or under development);

- Old and legacy systems to meet corporate needs for current and up to date knowledge management;

- Reliance on regular reviews and updates of report templates;

- Consistency between internal procedures from different sites of the organisation;

- System of control/check for consistency and accuracy on data entry and data reporting;

- Nonstandardisation of units of measurement.

In other words, standardised data models for E-TCs have significant impact on the efficient handling of test documents and reports. Specifically, practical reasons relate directly to the data format and their integration - or the possibility of integration - within the systems of knowledge management and quality control already in place. In many cases the core software of such systems was built in the 1960s and upgraded incrementally.

These reasons are, of course, of a strategic importance especially for manufacturers and the opportunity offered to either drive the formation of standards in data formats or resisting their implementation is depending on the fact that the operations of stakeholders in the TC business are built around data handling systems that have been developed through various stages during a long period and based on different technologies some of which are off-the-shelf software solutions and some other are proprietary and/or developed in house. The integration of said technologies is not seamless.

One stakeholder, whose core business is in the manufacturing but it is heavily engaged on R\&D whilst at same time operating several test facilities, reported that the process of data capture and management is not integrated in the business operations. They use several computer systems supporting different units, their test facilities have relatively modern Laboratory Information Management systems whilst the data are stored and handled via mainframes which are not co-located and operating on Fortran and Cobol - developed over a period of over 30 years; moreover, each unit runs its own software system independently and the interface with the operative units are on a Windows-based systems. 
Table 1

Stakeholders and their involvement in the test certificate value chain.

\begin{tabular}{|c|c|c|c|}
\hline Stakeholder & Role of TCs in the value chain & Supply/Demand & Notes \\
\hline Manufacturing sector & $\begin{array}{l}\text { Use of TCs in new product development, } \\
\text { production, sale and audit for traceability }\end{array}$ & $\begin{array}{l}\text { OEMs are the main hub for TCs. They request } \\
\text { TCs for the parts used in their manufacturing } \\
\text { activities and provide TCs to their } \\
\text { customers. }\end{array}$ & $\begin{array}{l}\text { TCs are complementary to all manufacturing } \\
\text { activities. }\end{array}$ \\
\hline Material test laboratories & $\begin{array}{l}\text { Production of test certificates and material } \\
\text { test reports }\end{array}$ & $\begin{array}{l}\text { Material test labs assess and certify the } \\
\text { characteristics of materials prior to their } \\
\text { integration within production lines or } \\
\text { assess/certify their performance whilst in } \\
\text { operation. }\end{array}$ & $\begin{array}{l}\text { Their business objective relates specifically } \\
\text { to the needs of the customers regarding the } \\
\text { details of reporting (from pass/fail to reports } \\
\text { of complex, detailed and integrated } \\
\text { certificates). }\end{array}$ \\
\hline Test machinery manufacturers & $\begin{array}{l}\text { Testing machinery manufacturers produce } \\
\text { the raw data from various testing procedures } \\
\text { to be included in the TCs. }\end{array}$ & $\begin{array}{l}\text { Test machinery manufacturers deal with the } \\
\text { production of the raw data deriving from } \\
\text { assessment and testing. They work closely } \\
\text { with software houses in order to integrate } \\
\text { data capture and handling. }\end{array}$ & $\begin{array}{l}\text { Their interests on the standardisation of } \\
\text { computer readable certificates are } \\
\text { complementary and strategic in the various } \\
\text { phases of development of their products. }\end{array}$ \\
\hline Software houses & $\begin{array}{l}\text { Provide the software necessary to export, } \\
\text { handle, archive and update test results. } \\
\text { Software products are used for capturing } \\
\text { raw data and integrate them into the } \\
\text { workflow as required by the procedures in } \\
\text { place by the customers. }\end{array}$ & $\begin{array}{l}\text { Work closely with test machine } \\
\text { manufacturers for data capture and } \\
\text { handling and with other customers to } \\
\text { provide software for data handling, } \\
\text { formatting an archiving. }\end{array}$ & $\begin{array}{l}\text { Software houses are intermediaries in the CT } \\
\text { value chain. }\end{array}$ \\
\hline $\begin{array}{l}\text { Materials research and } \\
\text { development } \\
\text { - University Departments; } \\
\text { - Public Research Centres; } \\
\text { - Private Research Organisations; } \\
\text { - Company's Research } \\
\text { Laboratories }\end{array}$ & $\begin{array}{l}\text { Their involvement with test certificates } \\
\text { ranges from theoretical-basic research to } \\
\text { applied industrial research and new product } \\
\text { development. R\&D on and with test } \\
\text { certificates is also an important aspect of } \\
\text { standard regulations and policy. }\end{array}$ & $\begin{array}{l}\text { The stakeholders are both suppliers in the } \\
\text { CT value chain and users. } \\
\text { Apart from the activities on the } \\
\text { characteristics of new materials research } \\
\text { and alternative uses of known materials, TCs } \\
\text { are valuable source of information for } \\
\text { translating R\&D into new products. }\end{array}$ & $\begin{array}{l}\text { Standardised measures of material } \\
\text { characteristics are crucial for new material } \\
\text { development and data reporting standards } \\
\text { are essential for further research and } \\
\text { dissemination. TC - Databases are also very } \\
\text { important in material science and } \\
\text { engineering and in R\&D activities. }\end{array}$ \\
\hline $\begin{array}{l}\text { Web-based publishers } \\
\text { (Publishers) }\end{array}$ & $\begin{array}{l}\text { Operations pertaining to test certificates } \\
\text { database design and management }\end{array}$ & $\begin{array}{l}\text { Web publisher are greatly interested in the } \\
\text { metadata behind the TCs as their core } \\
\text { business relates to the collection, } \\
\text { classification and re-sale of standard } \\
\text { documentation. }\end{array}$ & $\begin{array}{l}\text { The value of a TC for a web-based publisher } \\
\text { is nil. The metadata behind the E-TC has the } \\
\text { potential to open new avenues for business. }\end{array}$ \\
\hline Third party services providers & $\begin{array}{l}\text { Implementation of standardisation } \\
\text { procedures and system architecture, design, } \\
\text { including operation for development } \\
\text { implementation and maintenance }\end{array}$ & $\begin{array}{l}\text { The main activity of these stakeholders is } \\
\text { the design, implementation and } \\
\text { maintenance of TCs management systems. }\end{array}$ & $\begin{array}{l}\text { Standardised data model would increase } \\
\text { compatibility of function-specific data } \\
\text { management systems. }\end{array}$ \\
\hline Life cycle analysts & $\begin{array}{l}\text { Optimise data management process along } \\
\text { the life cycle of materials, keeps track of } \\
\text { materials' performance from the raw } \\
\text { materials used in the production process to } \\
\text { their behaviour once out in the marketplace } \\
\text { and finally, disposal. }\end{array}$ & $\begin{array}{l}\text { TCs constitute the main support } \\
\text { documentation for the study, assessment, } \\
\text { audit and end-of-life cycle strategies of } \\
\text { products. }\end{array}$ & $\begin{array}{l}\text { Particularly relevant in those sectors of } \\
\text { economic activities where the regulatory } \\
\text { framework is stringent (i.e. for security, } \\
\text { safety or public concern reasons) }\end{array}$ \\
\hline
\end{tabular}

At this point, one informant remarked that “... the situation is similar in any large OEM... at the moment any investment in data management equipment is not a sensible choice: the cost of dismissing old systems is high and disrupts operations and the implementation of a new [integrated] system will cause overreliance [of the company] on a supplier that wants to sell us their product and then charge us for licence fees and maintenance".

The main problem highlighted by material test laboratories is not only the integration of the certification system within the company's boundaries, but also the interface with their customers. Given the variety and the complexity of the transactions, test laboratories are increasingly implementing sophisticated and costly knowledge and information management systems. In the opinion of the respondents, the design and development of certificates knowledge management and quality control systems are the crucial aspects for an effective management of the procedures relating to the certification. In this realm they have expressed an extremely positively view on the introduction of standardised data models for E-TCs.

For material test machinery manufacturers, TCs are not integrated into their business/knowledge management system; however, they certainly constitute important inputs into the development and production of testing machinery. Moreover, test machine manufacturers make great use of standardised tests beyond those carried out on materials. In fact, data operations relating to tests machine configurations and test set-ups are perhaps the most important activities of this group of stakeholders since the content of specific tests, ultimately, influences the machines output. The use of standardised data formats would also affect the 'analytical' capabilities of testing machines especially for repeated tests such as 'fatigue' which require the pooling of data for 'failure stress' and 'cycles to failure' for the calculation of the S-N curve. The introduction of standardised data format would be a determinant for marketing and demonstration purposes of the machinery in different industrial contexts. Standard E-TC templates would therefore constitute valuable inputs into the development and marketing of test machinery.

The main problem highlighted by software houses, regarding the current running of business, relates directly to standardisation issues. The hurdle relates to the fact that test machines and software are integrated, therefore support for data capture, and transmission to next steps such as data handling, archiving and updating are at the core of services provided by software houses. Moreover, as two respondents from this class of stakeholders highlighted, the possibility for a software house, however large to impose its own standards is negligible yet, it is within the organisations' capabilities to provide novel software solutions to their customers since the current variety of data formats existing in the market already imposes on the software providers an extra load in adapting, calibrating and maintaining different TC management platforms.

In particular, the product manager/materials solutions of a software house stated that: "the general concept is desirable to the software houses for all the benefits associated with a standard data exchange format" but, the informant suggested, software houses have been investing time and resources into their own proprietary data formats and "the promotion of standardized data formats may not be perceived as in the best 
interest of the company". Instead, it would become convenient from the moment that providing "support for the new standard [is] perceived to be a competitive advantage to offset the costs associated with implementation". Of course immediate business streams deriving from the design and development of new data management systems and the introduction of the new formats to legacy systems, which are notoriously more demanding than new systems due to the presence of retrofittingassociated costs, constitute a consistent incentive for the promotion of standardised data formats.

The providers of software solutions are certainly targeting the customers' needs but the functionality of their products depends on the format of the data they are called out to handle. It is in fact from this particular aspect that depends any possibility of interoperability within different sites of the same client or between the clients and their business partners.

Informants from R\&D performers, including university departments, public and private research organisations and industrial laboratories, agree that standardised E-TC would certainly provide advantages in setting up certificates management infrastructures due to their ease of processing through electronic systems. In fact, working with standard templates will favour systems stability and an enhanced use of metadata materials pedigree, simulation processes, and data mining/big data activities which are only possible when data management solutions can provide consistent materials data.

The problem with the current state of affairs highlighted by the respondents involved in R\&D does not pertain directly to the conceptual and practical phases of transitioning away from a traditional paperbased system of document handling and the development of the potentiality of the existing/developing electronic system. Having already moved towards some form of E-TCs usually managed through laboratory information management systems, R\&D stakeholders are tackling the challenges posed by the lack of standardisation in this field in designing and setting up infrastructures able to handle, archive and manage large quantity of data taking into consideration the needs of their organisations, issue of confidentiality, the relations between the integration of nonco-located infrastructure and the need, diffusion and uses of TCs whilst at the same time, preserve the quality of the data therein contained for research purposes. In other words the lack of widely spread standardisation in the sector is a major barrier for collaboration with other departments of the same organisation - i.e. integration of R\&D-to-R\&D sites and R\&D-to-manufacturing - and with third parties for collaborative research projects and even for routine transactions. This aspect is very much determinant for the efficient work in material science and research centres in universities, and public and private research organisation which both produce huge quantity of materials data and require/use data from different sources or produced in past experiments. For this class of stakeholders, the presence of a standardised data format would mean that databases could be integrated whilst maintaining data consistency - "since the metadata behind the information is standard" - data-mining activities and other virtual applications carried out on larger sets would reap more benefits in terms of research results.

For publishers, the introduction of standard E-TC, as long as data and metadata therein included can be reliably handled by software applications to the point of flowing to the management infrastructure, would open a wide range of business opportunities. Key opportunities identified are the ability to search, correlate, analyse and report over data taken from the certificates obtained from different sources or from the same sources over time. Statistical tools can be employed to enquiry into the consistency of the certification processes but also in support of organisational tasks such as checking if the materials delivered are consistently compliant to the specifications required. This, in turn, provides an audit trail from the point of certification to production and sale; by virtue of the traceability that follows. This also allows collaborations and data-sharing within different functions of an organisation and with external partners. A further advantage of standard E-TCs would likely entail cost reduction associated to the need of repeat testing due to the parcelling out of tests into subtests whenever suitable tests have already been performed in the first place.

For third party services providers, the lack of a standardised format for E-TC constitutes a hindering factor in the optimisation of management processes and difficulties in tailoring management infrastructures to the need of the client. This mismatching, together with the great variety of needs of their clients, is the main hurdle in the core business of third party services providers.

According to our respondents, the introduction of standardised E-TCs would at least reduce uncertainty on the integration of TCs in the core business activities of the client companies and operational implementation steps can be better negotiated with the client needs. This, in turn would result in the opening of new possibilities for integration translating in benefits for both the service providers and their clients.

The case for a standardised computer readable test format is advanced also by life cycle analysts. The introduction and promotion of standard E-TCs would in fact have enormous advantages in terms of increasing certainty in the materials analysis because of the improved reliability of the correspondence between data and metadata. At the same time, procedures to link materials characteristics along the whole of the production process and its life cycle can be retrieved and traced back in order to verify and evaluate its performance. Also errors linked to human handling of non-standardised format of data and vagueness concerning evaluation methods can be minimised reducing time consuming and costly operations set out to control for these events.

\section{Discussion and conclusions}

One strong conclusion is the need for standardised machinereadable test certificates.

There is a generalised need for a computer readable standard test certificate for materials. This need is felt, albeit for different reasons, by all stakeholders situated along each link of the value chain of the materials sectors. In fact, most stakeholders conveyed the message that business prospects deriving from the introduction of a standard computer readable format are overall positives consisting in either cost reduction, increased efficiency of operations or novel business opportunities. For some stakeholders, opportunities are only identifiable through the indirect effects they have on the broader organisation's value generation activities and relate to either meeting their clients' needs or accruing reputation within the sector.

Standardisation of the data models can promote the implementation of information systems relying on state of the art knowledge management and quality control systems and breaks with the costly and constant upgrades of old legacy systems. Tangible benefits can be a larger scope for increasing opportunities to streamline operations and increase efficiency in data handling, storing, retrieving and updating that would be otherwise impossible. At the same time, operations for paper-based certificates, print outs of test results, and re-issues of updated versions for audit and traceability will be preserved since the requirements of current regulations would be met without incurring in additional costs.

Stakeholders independently highlight that, in principle, a collaborative approach to the design and implementation of a standardised computer readable certification process has the potential to overcome the negative effects that the presence of proprietary data formats might have especially with regards to the established data management approaches which have some market penetration but so far have not emerged as de facto standards.

The steps necessary to realise the transition towards the design and implementation of standardised data formats need to focus on the end result of a more efficient, less time consuming and cost saving way to achieve integration of the internal functions of an organisation pertaining the management of test certificates and the simplification of the activities linked to data transfer, handling, archiving and updating between the various stakeholders involved in mutual business 
transactions. The proviso is that the working parties avoid erecting barriers such as sponsoring the use of restricted, proprietary or not shared standard setting frameworks.

The analysis raises questions on the particular interests of the stakeholders and how these can influence the standard setting framework. The study highlights some critical issues.

A critical factor is that the introduction of different formats would inevitably increase the costs of transferring TCs between different units of the same organisation or between different organisations. Therefore, the choice of a common, appropriate format is of crucial importance. Any progress that limits the choice of languages that can be used to integrate old systems with new functionalities would necessarily erect high barriers to the standardisation process and therefore to the diffusion of standardised E-TCs. In other words, in order to take into consideration and minimise the negative effects at the critical stages identified, the standardisation process needs to be based on a format that, on the one hand, incorporates the state of the art without requiring expensive adjustments and, on the other hand, provides a sort of "lingua franca" that is compatible with the needs of all stakeholders concerned.

A final observation is that standardised data models are a type of semantic standards. The criticality of semantic standards has been recognised without doubt and relates to the innovation process from the early phase of blue sky-research to the phases of technology diffusion (Blind \& Gauch, 2009). This study confirms the hypothesis that standard data models are indeed part of the critical ICT infrastructure of a sector and their functions extend beyond the phase of domain definition/reduction of transaction costs as originally posited for semantic standards. Perhaps they should be considered as a cross-cutting issue explicitly integrated in the standardisation process in future fields of standardisation (Goluchowicz \& Blind, 2011).

Annex:

\begin{tabular}{|c|c|}
\hline Airbus France SAS & Hydro Aluminium Deutschland GmbH \\
\hline Alenia Aeronautica S.p.A & Imperial College \\
\hline Alstom Power & IncoTest UK, Special Metals Wiggins Ltd \\
\hline $\begin{array}{l}\text { The European body for the development } \\
\text { of global aerospace standards } \\
\text { ASD-STAN }\end{array}$ & Instron - A Division of ITW Ltd. \\
\hline $\begin{array}{l}\text { The American Society for Testing and Ma- } \\
\text { terials ASTM International }\end{array}$ & $\begin{array}{l}\text { Manchester Institute of Innovation } \\
\text { Research, The University of } \\
\text { Manchester }\end{array}$ \\
\hline The British Standard Institution & MSC Software Corporation \\
\hline CAESAR Systems & MDAO Technologies Ltd. \\
\hline $\begin{array}{l}\text { China Electronics Standardization Insti- } \\
\text { tute (CESI) }\end{array}$ & UK - National Physical Laboratory \\
\hline $\begin{array}{l}\text { Digital Curation Centre, University of } \\
\text { Edinburgh }\end{array}$ & SOASYS Ltd. \\
\hline Doosan Babcock Energy Limited & $\begin{array}{l}\text { The University of Queensland, School } \\
\text { of ITEE }\end{array}$ \\
\hline EC JRC Institute for Energy & $\begin{array}{l}\text { Toyo University, Faculty of Regional } \\
\text { Development Studies }\end{array}$ \\
\hline Exova Group plc & University of Southampton \\
\hline $\begin{array}{l}\text { Federal Institute for Materials Research } \\
\text { and Testing (BAM) }\end{array}$ & Volvo Aero Corporation \\
\hline Granta Design Limited & $\begin{array}{l}\text { Aeronautical Research and Test } \\
\text { Institute (VZLÚ a.s.) }\end{array}$ \\
\hline $\begin{array}{l}\text { High Temperature Mechanical Testing } \\
\text { Committee }\end{array}$ & \\
\hline
\end{tabular}

Other participants, whose names are undisclosed, include multinational corporations and organisations operating in the materials sector, in the energy sector and operating in data management for science and technology.

\section{Acknowledgements}

The author is particularly indebted to Timothy Austin (project manager), Chris Bullough (chair of the CEN Workshop Agreement 16200),
David Leal and Malcolm Loveday for their guidance and support during the 15 month's research, the workshop participants for the information and the knowledge they have shared, Jonathan Aylen and the members of the Writing Club at MIoIR led by Elvira Uyarra for insightful comments and suggestions. The author is grateful to two anonymous reviewers for their comments and suggestions on the earlier version of the manuscript. The financial support of the EC (CWA 16200:2010 E) and EFTA for CEN/WS ELSSI-EMD is gratefully acknowledged. Usual caveats apply.

\section{References}

BS EN 12150, 2004. Glass in building. Thermally toughened soda lime silicate safety glass. Evaluation of conformity/Product standard. BSI.

BS EN 14449:2005, 2005. Glass in building - Laminated glass and laminated safety glass Evaluation of conformity/Product standard. BSI

BS EN 1279-2, 2002. Glass in building-Insulating glass units-long term test method and requirements for moisture penetration. BSI.

BS EN 1279-3, 1998. Long term test method and requirements for gas leakage rate and for gas concentration tolerances. BSI.

BS EN 1279-6, 2002. Insulating glass units. Methods and rules of products quality assurance. BSI.

Parsons, D., Chatterton, J., Nicholls, J., 2011. Carbon Brainprint case study - Ceramic coating for Jet engine turbine Blades. Cranfield University (July 2011 available at: http://www.carbonbrainprint.org.uk/pdf/CBrainprint-CS01-JetTurbines.pdf Accessed February, 2015).

Akerlof, G.A., 1970. The market for" lemons": quality uncertainty and the market mechanism. Q. J. Econ. 84 (3), 488-500.

Leland, H.E., 1979. Quacks, lemons, and licensing: a theory of minimum quality standards. J. Polit. Econ. 87 (6), 1328-1346.

Ronnen, U., 1991. Minimum quality standards, fixed costs, and competition. RAND J. Econ. 22 (4), 490-504.

Dranove, D., Jin, G.Z., 2010. Quality disclosure and certification: Theory and practice. National Bureau of Economic Research No. w15644

David, P.A., 1987. Some new standards for the economics of standardization in the information age. In: Dasgupta, P., Stoneman, P.L. (Eds.), The Economic policy and technological performance. Cambridge University Press, pp. 206-239.

Allen, R.H., Sriram, R.D., 2000. The role of standards in innovation. Technol. Forecast. Soc Chang. 64 (2), 171-181.

Tassey, G., 2000. Standardization in technology-based markets. Res. Policy 29 (4), 587-602.

Langlois, R.N., 2001. Technological standards, innovation, and essential facilities. Dynamic competition and public policy. Technol. Innov. Antitrust Issues 193.

Chen, K.M., Liu, R.J., 2005. Interface strategies in Modular product Innovation. Technovation 25 (7), 771-782.

Hyvättinen, H., 2006. Interface standards and creating innovation markets-implications on SMEs in a technology programme. Technovation 26 (2), 262-273.

David, P.A., Greenstein, S., 1990. The economics of compatibility standards: an introduction to recent research 1. Econ. Innov. New Technol. 1 (1-2), 3-41.

Utterback, J.M., 1994. Mastering the Dynamics of Innovation: How Companies can Seize Opportunities in the Face of Technological Change (Cambridge, MA).

Blind, K., 2004. The economics of standards. Theory, evidence, policy. Edward Elgar, Cheltenham.

Katz, M.L., Shapiro, C., 1985. Network externalities, competition, and compatibility. Am. Econ. Rev. 7 (3), 424-440.

Katz, M.L., Shapiro, C., 1994. Systems competition and network effects. J. Econ. Perspect. 8 (2), 93-115.

Shapiro, C., Varian, H.R., 1999. Information Rules: A Strategic Guide to the Network Economy. Harvard Business School Press, Boston.

Shapiro, C., Varian, H.R., 2003. The art of standards wars. In: Garud, R., Kumaraswamy, A. Langlois, R. (Eds.), Managing in the Modular Age: Architectures, Networks and Organisation. Blackwell Publisher Ltd., Oxford, UK.

David, P.A., Bunn, J.A., 1988. The economics of gateway technologies and network evolution: lessons from electricity supply history. Inf. Econ. Policy 3 (2), 165-202.

David, P.A., 1985. Clio and the economics of QWERTY. Am. Econ. Rev. 75 (2), 332-337.

Cusumano, M.A., Mylonadis, Y., Rosenbloom, R.S., 1992. Strategic maneuvering and massmarket dynamics: the triumph of VHS over beta. Bus. Hist. Rev. 66 (01), 51-94.

Garud, R., Jain, S., Kumaraswamy, A., 2002. Institutional entrepreneurship in the sponsorship of common technological standards: the case of sun Microsystems and java. Acad. Manag. J. 45 (1), 196-214.

Gallagher, S.R., 2012. The battle of the blue laser DVDs: the significance of corporate strategy in standards battles. Technovation 32 (2), 90-98.

Ortiz Jr., S., 2011. The problem with cloud-computing standardization. Computer 44 (7), 13-16.

Bandyopadhyay, D., Sen, J., 2011. Internet of things: applications and challenges in technology and standardization. Wirel. Pers. Commun. 58 (1), 49-69.

Tsai, C.W., Lai, C.F., Vasilakos, A.V., 2014. Future internet of things: open issues and challenges. Wirel. Netw 20 (8), 2201-2217.

Chiesa, V., Manzini, R., Toletti, G., 2002. Standard-setting processes: evidence from two case studies. R\&D Manag. 32 (5), 431-450.

Suarez, F.F., 2004. Battles for technological dominance: an integrative framework. Res. Policy 33 (2), 271-286. 
Van Wegberg, M., 2004. Standardization process of systems technologies: creating a balance between competition and cooperation. Tech. Anal. Strat. Manag. 16 (4), 457-478.

Jakobs, K., 2006. Shaping user-side innovation through standardisation: the example of ICT. Technol. Forecast. Soc. Chang. 73 (1), 27-40.

Gauch, S., Blind, K., 2015. Technological convergence and the absorptive capacity of standardisation. Technol. Forecast. Soc. Chang. 91, 236-249.

Dosi, G., 1982. Technological paradigms and technological trajectories: a suggested interpretation of the determinants and directions of technical change. Res. Policy 11 (3), $147-162$.

Blind, K., Gauch, S., 2009. Research and standardisation in nanotechnology: evidence from Germany. J. Technol. Transf. 34 (3), 320-342.

Goluchowicz, K., Blind, K., 2011. Identification of future fields of standardisation: an explorative application of the Delphi methodology. Technol. Forecast. Soc. Chang. 78 (9), 1526-1541.

Xu, X., 2012. From cloud computing to cloud manufacturing. Robot. Comput. Integr. Manuf. 28 (1), 75-86.

Kádár, B., Terkaj, W., Sacco, M., 2013. Semantic virtual factory supporting interoperable modelling and evaluation of production systems. CIRP Ann. Manuf. Technol. 62 (1), 443-446.

Westkämper, E., Jendoubi, L., 2003. Smart factories-manufacturing environments and systems of the future. Proceedings of the 36th CIRP International Seminar on Manufacturing Systems, pp. 13-16 June.

Davis, J., Edgar, T., Porter, J., Bernaden, J., Sarli, M., 2012. Smart manufacturing, manufacturing intelligence and demand-dynamic performance. Comput. Chem. Eng. 47, 145-156.

Ward, C.H., Warren, J.A., Hanisch, R.J., 2014. Making materials science and engineering data more valuable research products. Integrating Mater. Manuf. Innov. 3 (1), 1-17.

Swindells, N., 2002. Communicating materials information: product data technology for materials. Int. Mater. Rev. 47 (1), 31-46.

Cascini, G., Giovani, G., Rissone, P., Rotini, F., 2005. Integrated design of turbomachinery through a STEP-XML platform for data exchange. Proc. Inst. Mech. Eng. B J. Eng. Manuf. 219 (7), 547-554.

Moreno, A., Cappellaro, F., Masoni, P., Amato, A., 2011. Application of product data technology standards to LCA data. J. Ind. Ecol. 15 (4), 483-495.

Orchard, S., Hermjakob, H., Julian, R. K., Runte, K., Sherman, D., Wojcik, J., ... \& Apweiler, R (2004). Common interchange standards for proteomics data: public availability of tools and schema. Report on the proteomic standards initiative workshop, 2nd annual HUPO congress, Montreal, Canada, 8-11th October 2003. Proteomics, 4(2), 490-491.

Orchard, S., Binz, P.A., Jones, A.R., Vizcaino, J.A., Deutsch, E.W., Hermjakob, H., 2013. Preparing to work with big data in proteomics - a report on the HUPO-PSI spring workshop. Proteomics 13 (20), 2931-2937.
Poore, B.S., 2011. Users as essential contributors to spatial cyberinfrastructures. Proc. Natl. Acad. Sci. 108 (14), 5510-5515.

Freeman, R.E., 1984. Strategic Management: A Stakeholder Approach. Pitman, Boston, MA

Freeman, R.E., Miles, S., 2006. Stakeholders: Theory and Practice. Oxford University Press. Fassin, Y., 2009. The stakeholder model refined. J. Bus. Ethics 84 (1), 113-135.

CEN CWA 16762:2014, 2014. ICT Standards in Support of an eReporting Framework for the Engineering Materials Sector by Bullough, C., Faget, A., Virgili, A., Leal, D., Rumble, J., Loveday, M., Austin, T. CEN, Brussels.

Salado, A., Nilchiani, R., 2013. Contextual- and behavioral-centric stakeholder identification. Procedia Comput. Sci. 16, 908-917.

De Vries, H., Verheul, H., Willemse, H., 2003. Stakeholder identification in IT standardization processes, standard making: a critical research frontier for information systems. MISQ Special Issue Workshop Seattle, WA- 2003, pp. 92-107.

Saltzman, J., Chatterjee, S., Raman, M., 2008. A framework for ICT standards creation: the case of ITU-T standard H. 350. Inf. Syst. 33 (3), 285-299.

Westbrook, J.H., 2003. Materials data on the internet. Data Sci. J. 2, 198-212.

Reason, P., Bradbury, H. (Eds.), 2001. Handbook of Action Research: Participative Inquiry and Practice. Sage Publications.

Eisenhardt, K.M., 1989. Building theories from case study research. Acad. Manag. Rev. 14 (4), 532-550.

Meredith, J., 1998. Building operations management theory through case and field research. J. Oper. Manag. 16 (4), 441-454.

Yin, R.K., 2013. Case Study Research: Design and Methods. 5th edition. Sage publications.

CEN CWA 16200:2010, 2010. A Guide to the Development and Use of Standards Compliant Data Formats for Engineering Materials Test Data by Bullough, C., Austin, T., Gagliardi, D. Loveday, M., Leal, D. CEN, Brussels.

Austin, T., Bullough, C., Gagliardi, D., Leal, D., Loveday, M., 2013. Prenormative research into standard messaging formats for engineering materials data. Int. J. Digit. Curation 8 (1), 5-13.

Dimitri Gagliardi is a Research Fellow at the Manchester Institute of Innovation Research The University of Manchester. He received his $\mathrm{PhD}$ in Economics and Institutions from the University of Bologna. Dr. Gagliardi has actively been engaged in economic analysis and applied research. His interests are in innovation and business dynamics in high tech/ knowledge intensive sectors; economics of innovation; science, technology and innovation management and policy. 